\title{
Identification of five novel arginine vasopressin gene mutations in patients with familial neurohypophyseal diabetes insipidus
}

\author{
DAN TIAN ${ }^{* 1}$, JING CEN* ${ }^{*}$ MIN NIE and FENG GU \\ Department of Endocrinology, Key Laboratory of Endocrinology, Ministry of Health, Peking Union Medical College Hospital, \\ Peking Union Medical College and Chinese Academy of Medical Sciences, Beijing 100730, P.R. China
}

Received September 8, 2015; Accepted May 24, 2016

DOI: $10.3892 /$ ijmm.2016.2703

\begin{abstract}
Familial neurohypophyseal diabetes insipidus (FNDI) is a genetic disorder presenting with polyuria and polydipsia and is caused by mutations in the arginine vasopressin-neurophysin II ( $A V P-N P I I)$ gene. The clinical manifestations of this disorder vary greatly depending on different mutations. The present study reports the genetic, clinical and biochemical characteristics of patients with FNDI caused by five novel mutations. Ten patients encompassing two pedigrees and four individual cases diagnosed with FNDI were included. Biochemical markers and magnetic resonance imaging (MRI) were evaluated and genomic DNA was sequenced. The results revealed that age at onset ranged from 1.0 to 11.0 years. Daily urine volumes ranged from 2.0 to 12.0 liters. One patient had mental retardation and three patients had puberty retardation; one patient had nausea, vomiting and mental retardation; and two patients had fever. Treatments, if given, included desmopressin and vasopressin tannate. Posterior pituitary T1-weighted MRI high-intensity signals were absent in two cases and present in four cases. Sequencing revealed five novel mutations in the AVP-NPII gene. On the whole, the findings of the present study indicate that FNDI exhibits different clinical manifestations and a diverse age at onset. Posterior pituitary MRI does not provide a definite diagnosis of FNDI. We also identified five novel $A V P$-NPII mutations. Thus, an enhanced understanding of FNDI pathogenesis may provide a basis for the development of presymptomatic FNDI diagnotic tools.
\end{abstract}

Correspondence to: Dr Feng Gu, Department of Endocrinology, Key Laboratory of Endocrinology, Ministry of Health, Peking Union Medical College Hospital, Peking Union Medical College and Chinese Academy of Medical Sciences, Beijing 100730, P.R. China E-mail: gufeng@gusmedsci.cn

Present address: ${ }^{1}$ Department of Nuclear Medicine, The First Affiliated Hospital, College of Medicine, Zhejiang University, 79 Qingchun Road, Hangzhou, P.R. China

*Contributed equally

Key words: arginine vasopressin-neurophysin II gene, gene mutation, familial neurohypophyseal diabetes insipidus

\section{Introduction}

Familial neurohypophyseal diabetes insipidus (FNDI) is a rare heterogeneous single-gene disorder caused by mutations in the arginine vasopressin-neurophysin II gene (AVP-NPII, OMIM:304900). The symptoms of FNDI include urine overproduction (polyuria) and excessive thirst (polydipsia). The familial type of the disease most commonly exhibits autosomal dominance, although rare cases of autosomal recessive FNDI have been reported $(1,2)$. FNDI encompasses approximately $1 \%$ of all central diabetes insipidus (CDI) cases (3).

To date, at least 70 mutations causing FNDI have been reported and all mutations are in the $2.5 \mathrm{~kb} A V P-N P I I$ gene (GenBank accession no. M11166), which is located on chromosome $20 \mathrm{p} 13$ (4). The AVP-NPII gene consists of three exons and two introns, and encodes the 164-amino acid preprovasopressin protein (4). Direct sequencing of the AVP-NPII gene of a patient with FNDI revealed a heterozygous GAG deletion mutation in exon 2 , which results in an in-frame deletion of a glutamic acid residue (c.232_234delGAG; p.Glu78del). The mutation yields an abnormal AVP precursor lacking Glu78 in its neurophysin II (NPII) moiety (4). As the NPII protein promotes intracellular AVP transport (5), the mutation of NPII affects the transport of AVP. Another study included 15 Turkish patients with CDI or nephrogenic diabetes insipidus, wherein two patients had AVP-NPII mutations (6).

Despite the number of studies describing FNDI, the clinical and hereditary features of this disease remain incompletely documented. In the present study, we report the diagnosis, as well as the hereditary and clinical characteristics of FNDI in 10 Chinese patients. The AVP-NPII gene was amplified from genomic DNA samples and sequenced to provide a comprehensive analysis of the mutations present in these patients.

\section{Patients and methods}

Study subjects. Sixteen Chinese patients diagnosed with diabetes insipidus and were receiving treatments at the Department of Endocrinology of the Peking Union Medical College Hospital (People's Republic of China) between July 2008 and December 2012 were included in this study. Among them, six patients were found to have nephrogenic diabetes insipidus and were not included. Blood sample screening of the families of the 10 remaining patients revealed two pedigrees (pedi- 
Table I. Primers use for the amplification the arginine vasopressin-neurophysin II (AVP-NPII) gene.

\begin{tabular}{lcc}
\hline AVP-NPII gene & Forward & Reverse \\
\hline Exon 1 & 5'-AGCCCCTCGGTTCCTCTTAC-3' & 5'-CCGAACTTCCCCTAAAGGCTAC-3' \\
Exons 2 and 3 & 5'-GTCACCGAGAGGTCATCCAAG-3' & 5'-AATTCGCCCTGTCCCTCGGTCT-3'
\end{tabular}

gree 1, 1 proband and five patients; and pedigree 2,1 proband). The Ethics Committee of the Peking Union Medical College Hospital approved the study protocol, and all patients provided written informed consent.

Diagnostic criteria of patients with FNDI/INDI. The diagnostic criteria of FNDI were as follows: i) clinical manifestations of polydipsia and polyuria, with a 24-h urine volume of $>4-10$ liters and a urine specific gravity of $<1.005$; ii) complete diabetes insipidus was defined as a blood osmotic pressure of $>295 \mathrm{mmol} /\left(\mathrm{kg} \cdot \mathrm{H}_{2} \mathrm{O}\right)$, no obvious alteration of the urine volume, and a urine osmotic pressure lower than the blood osmotic pressure if the osmotic pressure of the urine does not rise following water deprivation; and iii) the presence or absence of high-intensity signals at the posterior pituitary in magnetic resonance imaging (MRI) of the saddle area, except for CDI secondary to primary tumors of the central nervous system. The MRI scan of the saddle area was performed for six patients with FNDI.

Blood sampling and DNA extraction. Peripheral venous blood samples were collected from probands and pedigree members. Samples were stored at $-20^{\circ} \mathrm{C}$. Genomic DNA was extracted from whole blood samples using a genomic DNA extraction kit (Qiagen, Venlo, The Netherlands).

Polymerase chain reaction (PCR) amplification and gel electrophoresis. The DNA segments containing exon 1 and exons 2-3 of the AVP-NPII gene were amplified by PCR and directly sequenced using the primers listed in Table I. PCR was performed in a 30- $\mu 1$ reaction volume under the following conditions: $95^{\circ} \mathrm{C}$ for $5 \mathrm{~min}, 35$ cycles of $94^{\circ} \mathrm{C}$ for $30 \mathrm{sec}, 61^{\circ} \mathrm{C}$ (for exon 1) or $58^{\circ} \mathrm{C}$ (for exons 2 and 3) for $30 \mathrm{sec}$, and $72^{\circ} \mathrm{C}$ for $1 \mathrm{~min}, 72^{\circ} \mathrm{C}$ for $10 \mathrm{~min}$, and $4^{\circ} \mathrm{C}$ for $10 \mathrm{~min}$ (Bio-Rad, Hercules, CA, USA). The amplification products were analyzed by $1.5 \%$ agarose gel electrophoresis and sequenced by a commercial service provider (SinoGenoMax Co., Ltd., Beijing, China). The function of the mutated gene was predicted using PolyPhen-2 software.

\section{Results}

Pedigree and inclusion of patients with FNDI. A total of sixteen patients were screened, including 10 members from a single pedigree, the proband, the proband's mother (these together, $\mathrm{n}=12$ ), and four unrelated sporadic cases of INDI. However, only $10(62.5 \%)$ of these patients met the requirements for the clinical diagnosis of FNDI, including five cases from the same pedigree. All subjects exhibited clinically diagnosed polydipsia and polyuria. The FNDI patient pedigree charts are shown in Fig. 1.
Clinical and demographic characteristics of patients with FNDI. The clinical characteristics of the patients with FNDI/INDI are summarized in Table II. The age at onset ranged from 1.0 to 11.0 years, although definite diagnosis occurred much later (between 3.7 and 50+ years). Urine volumes ranged from 2.0 to 12 liters/day. One patient had mental retardation and three patients had puberty retardation (40\%), one patient (10\%) had nausea, vomiting and mental retardation, and two patients $(20 \%)$ complained of sustained intermittent fever. Patients were treated with desmopressin $(7 / 10,70 \%)$, vasopressin tannate $(1 / 10 ; 10 \%)$, or no medication $(2 / 10,20 \%)$ (Table II).

Early remission of CDI in one patient. Of note, for patient I:1, the estimated 24-h urine volume was 10.0-20.0 liters at a young age (Fig. 1); however, the patient did not seek medical intervention despite these typical signs of diabetes insipidus. At the age of 56.0 years, this patient had a sharply decreased 24-h urine volume of 4.0-5.0 liters/day (Table II); however, hyperosmolarity of the blood, hyposmolarity of the urine, and a low urine specific gravity were reported for this patient.

MRI imaging. Four patients were found to have hydroureter and/or hydronephrosis and were excluded from the imaging analysis (Fig. 2). The MRI scan of the saddle area was performed for six patients, and high-intensity signals were observed on T1-weighted images at the posterior pituitary in four patients, while the signals disappeared in the other two patients. In addition, the MRI data revealed the thickening of the pituitary stalk in two of the six patients (Fig. 2).

AVP-NPII mutations in patients with FNDI/INDI. The PCR products of the $A V P-N P I I$ gene from peripheral blood genomic DNA were analyzed by electrophoresis. The sequencing data and localization of the AVP-NPII gene are shown in Fig. 3. The sequencing of the proband NYH revealed a heterozygous frameshift mutation in exon 1 (c.2delT, p.M1_T4del) (Fig. 3A). These findings were in agreement with the sequencing results obtained for family members I:1, II:3, III:1 and III:3 (Fig. 1) (data not shown). The frameshift mutation was validated by cloning and sequencing. In addition, sequencing of the proband QSH revealed a heterozygous point mutation in exon 1 (c.50C>A, p.S17Y) (Fig. 3B), which was consistent with a mutation found in the proband's mother (data not shown). Furthermore, sequencing of the proband $\mathrm{CC}$ revealed a heterozygous point mutation in exon 2 (c.127C $>$ G, p.P43A) (Fig. 3C). Of note, the sequencing data of the proband's father displayed no gene aberrations (data not shown). Of note, sequencing of the proband CSY revealed a heterozygous point mutation in exon 3 (c.329G>A, p.C110Y) (Fig. 3D). Finally, sequencing of the proband GJY revealed a deletion/frameshift mutation in exon 1 (c.52-54delTCC, p.S18del) (Fig. 3E). The newly identi- 


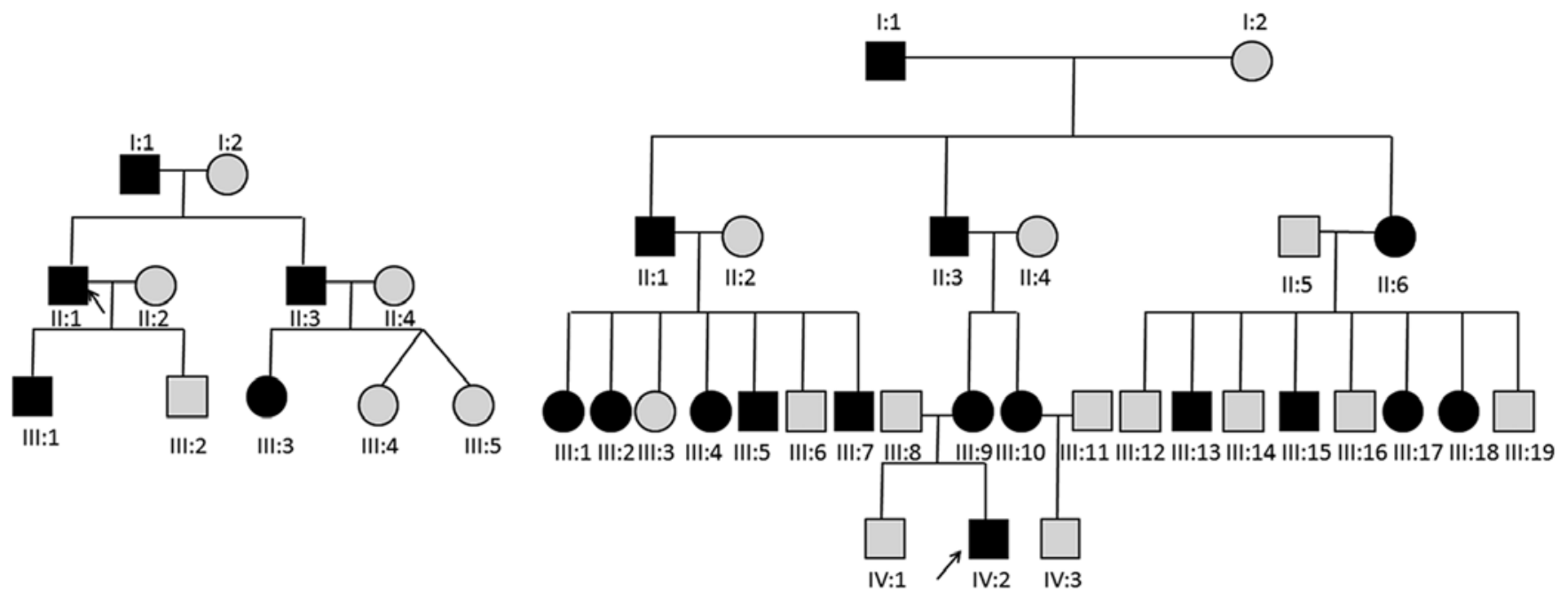

Family 1

Family 2

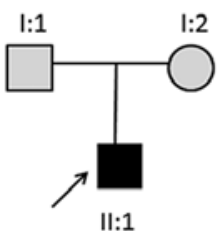

Family 3

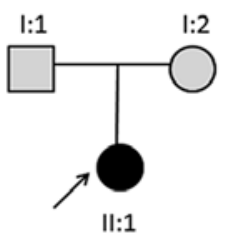

Family 4

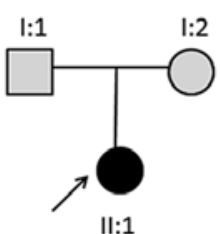

Family 5

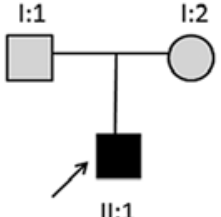

Family 6

Figure 1. Pedigree chart of patients with familial neurohypophyseal diabetes insipidus (FNDI). Arrows indicates probands; $\square$, male patients; $\circ$, female patients; $\mathbf{-} / \mathbf{\bullet}$, patients with symptomatic FNDI.

Table II. Clinical characteristics of the patients with FNDI ( $n=6)$ and the patients with INDI $(n=4)$.

\begin{tabular}{|c|c|c|c|c|c|c|c|c|c|c|}
\hline \multirow[b]{2}{*}{ Characteristic } & \multicolumn{10}{|c|}{ Pedigree no. } \\
\hline & 1I:1 & 1II: 1 & 1II:3 & 1III:1 & 1III:3 & 2 & 3 & 4 & 5 & 6 \\
\hline Gender & M & M & M & M & $\mathrm{F}$ & M & M & $\mathrm{F}$ & $\mathrm{F}$ & M \\
\hline Onset age (years) & UK & 5 & 6 & 4 & 5 & 11 & 1 & 5 & 6 & 11 \\
\hline $\begin{array}{l}\text { Definite age at } \\
\text { diagnosis (years) }\end{array}$ & 56 & 30 & 29 & 7.7 & 6.4 & 18 & 8 & 22 & 19 & 28 \\
\hline Disease course (years) & $50^{+}$ & 25 & 23 & 3.7 & 1.4 & 7 & 9 & 17 & 13 & 17 \\
\hline Polydipsia & + & + & + & + & + & + & + & + & + & + \\
\hline $\begin{array}{l}\text { Urine volume } \\
\text { (liters/24 h) }\end{array}$ & $4.0-5.0$ & $5.5-7.0$ & $6.0-7.0$ & 3 & 2 & 10 & $3.0-4.0$ & $10.0-12.0$ & $4.0-6.0$ & $6.0-10.0$ \\
\hline $\begin{array}{l}\text { Nocturia } \\
\text { (times/night) }\end{array}$ & $1 / 2$ & $3 / 5$ & $2 / 3$ & $1 / 2$ & $1 / 2$ & $2 / 3$ & $2 / 3$ & $3 / 4$ & 0 & UK \\
\hline Fever $^{\mathrm{a}}$ & & & & + & & & + & & & \\
\hline Nausea/vomiting & & & & & & & + & & & \\
\hline Mental retardation & & & & & & & + & & & \\
\hline Puberty retardation & Retardation & Retardation & Retardation & N/A & N/A & Normal & Normal & Normal & Normal & Normal \\
\hline Microsomia & N/A & N/A & N/A & $-1 \mathrm{SD}$ & $-2 \mathrm{SD}$ & $-1 \mathrm{SD}$ & $-2 \mathrm{SD}^{\mathrm{b}}$ & N/A & Normal & N/A \\
\hline Family history & Yes & Yes & Yes & Yes & Yes & Yes & No & No & No & No \\
\hline Treatment & Untreated & $\begin{array}{l}\text { Desmo- } \\
\text { pressin }\end{array}$ & $\begin{array}{l}\text { Desmo- } \\
\text { pressin }\end{array}$ & $\begin{array}{l}\text { Desmo- } \\
\text { pressin }\end{array}$ & Untreated & $\begin{array}{l}\text { Vasopressin } \\
\text { tannate }\end{array}$ & $\begin{array}{l}\text { Desmo- } \\
\text { pressin }\end{array}$ & $\begin{array}{l}\text { Desmo- } \\
\text { pressin }\end{array}$ & $\begin{array}{l}\text { Desmo- } \\
\text { pressin }\end{array}$ & $\begin{array}{l}\text { Desmo- } \\
\text { pressin }\end{array}$ \\
\hline $\begin{array}{l}\text { Efficacy ( } 24-\mathrm{h} \\
\text { urine volume, liters) }\end{array}$ & N/A & $2.0-3.0$ & $2.0-3.0$ & 1.5 & N/A & 2 & $1.5-2.0$ & $2.0-3.0$ & $1.0-2.0$ & 2.5 \\
\hline
\end{tabular}

a Sustained intermittent fever; btreatment with growth hormone. +, presence of clinical manifestation; UK, unknown; N/A, not available; FNDI, familial neurohypophyseal diabetes insipidus; INDI, idiopathic neurohypophyseal diabetes insipidus. 
Table III. AVP-NPII mutations in familial neurohypophyseal diabetes insipidus (FNDI) probands and inpatients with idiopathic neurohypophyseal diabetes insipidus (INDI).

\begin{tabular}{|c|c|c|c|c|c|c|}
\hline \multirow{2}{*}{$\begin{array}{l}A V P-N P I I \\
\text { mutations }\end{array}$} & \multicolumn{6}{|c|}{ Case ID } \\
\hline & NYH & QSH & $\mathrm{CC}$ & CSY & GJY & YSH \\
\hline Coding region & Exon 1 & Exon 1 & Exon 2 & Exon 3 & Exon 1 & $\begin{array}{c}\text { No detected } \\
\text { mutations }\end{array}$ \\
\hline cDNA mutation & c. 2 delT & c. $.50 \mathrm{C}>\mathrm{A}$ & c. $127 \mathrm{C}>\mathrm{G}$ & c. $329 \mathrm{C}>\mathrm{A}$ & C.52-54delTCC & \\
\hline Amino acid change & p.M1_T4del & p.S17Y & p.P43A & p.C110Y & p.S18del & \\
\hline Type of mutation & $\begin{array}{l}\text { Frameshift } \\
\text { mutation }\end{array}$ & $\begin{array}{l}\text { Missense } \\
\text { mutation }\end{array}$ & $\begin{array}{l}\text { Missense } \\
\text { mutation }\end{array}$ & $\begin{array}{l}\text { Missense } \\
\text { mutation }\end{array}$ & $\begin{array}{l}\text { Frameshift } \\
\text { mutation }\end{array}$ & \\
\hline Protein localization & SP-19-16 & SP-3 & NP-II-12 & NP-II-79 & SP-2 & \\
\hline Mode of inheritance & $\begin{array}{l}\text { Autosomal } \\
\text { dominant }\end{array}$ & $\begin{array}{l}\text { Autosomal } \\
\text { dominant }\end{array}$ & $\begin{array}{l}\text { Autosomal } \\
\text { dominant }\end{array}$ & $\begin{array}{l}\text { Autosomal } \\
\text { dominant }\end{array}$ & $\begin{array}{l}\text { Autosomal } \\
\text { dominant }\end{array}$ & \\
\hline Father/mother origin & Father & Mother & Unknown & Unknown & Unknown & \\
\hline Family history & Yes & Yes & No & No & No & No \\
\hline $\begin{array}{l}\text { Function prediction } \\
\text { (PolyPhen-2) }\end{array}$ & & $\begin{array}{l}\text { Moderately } \\
\text { impaired }\end{array}$ & $\begin{array}{l}\text { Moderately } \\
\text { impaired }\end{array}$ & $\begin{array}{l}\text { Moderately } \\
\text { impaired }\end{array}$ & & \\
\hline
\end{tabular}

The father of proband CSY had clinical manifestations of polydipsia and polyuria; however, no arginine vasopressin-neurophysin II (AVP-NPII) mutation could be detected. The mother of proband CSY had normal clinical manifestations, and blood samples were not obtained. The parents of proband YSH had normal clinical manifestations, and blood samples were not obtained.

A

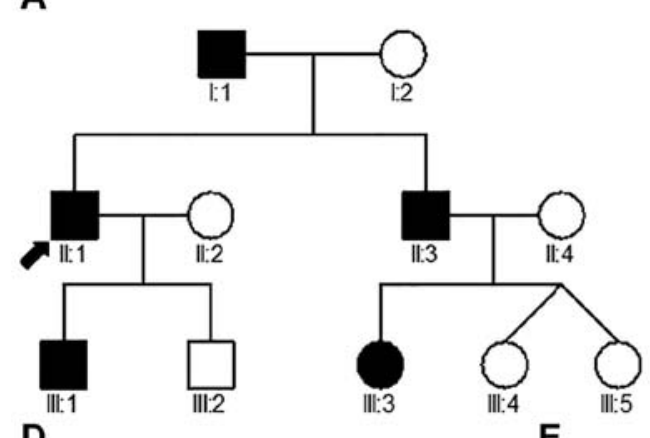

D

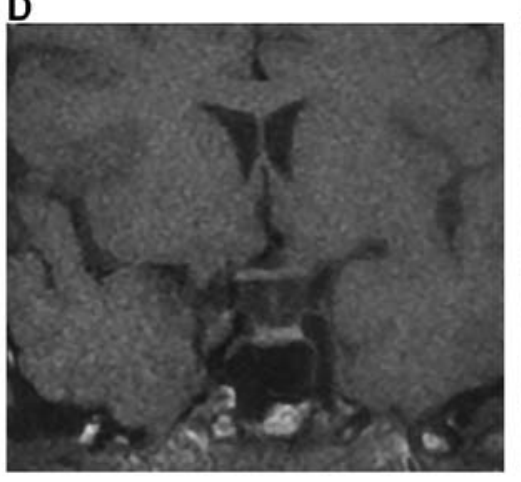

B

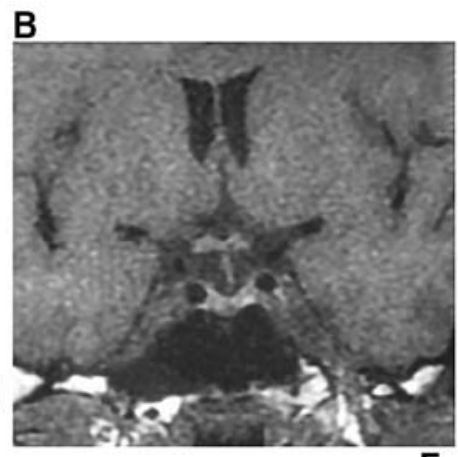

C
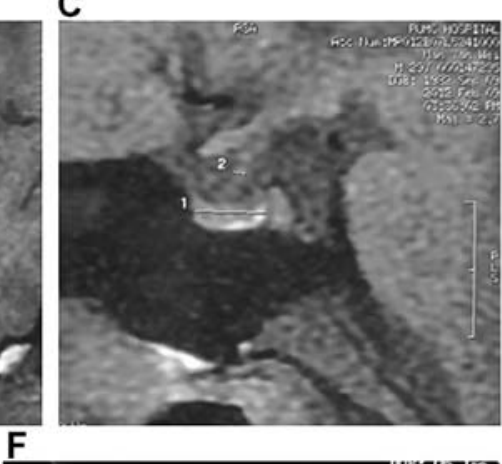
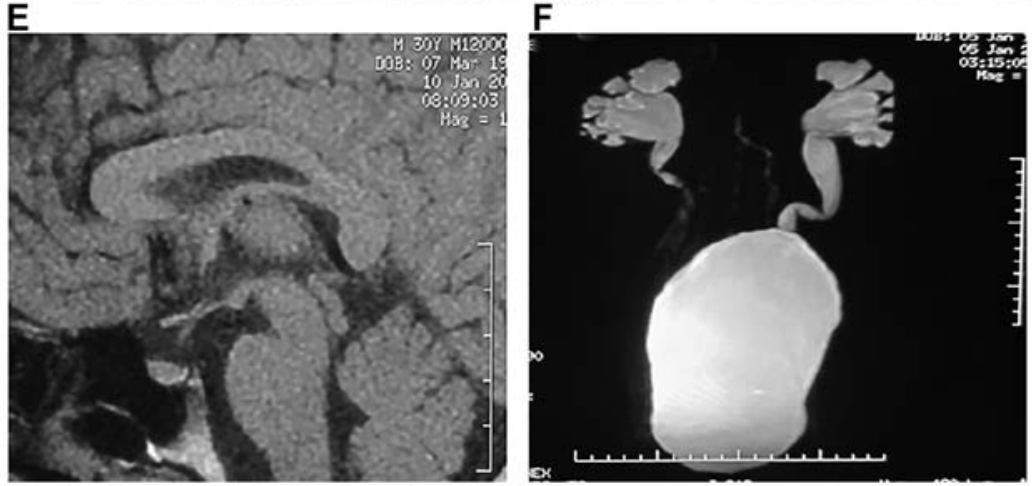

Figure 2. Pedigree chart and imaging data of members of pedigree 1. (A) Chart of pedigree 1. Arrows indicate probands; $\square$, male patients; $\bigcirc$, female patients;

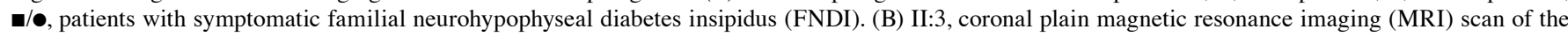
third saddle region. (C) II:3, sagittal plain MRI scan of the third saddle region (slight thickening of the pituitary stalk and the presence of high-intensity signals at the posterior pituitary). (D) II:1, coronal plain MRI scan of the first saddle region. (E) II:1, sagittal plain MRI scan of the first saddle region (presence of high-intensity signals at the posterior pituitary). (F) II:1, magnetic resonance urography (MRU), apparent bilateral hydronephrosis and hydrocalycosis occurred, and the renal pelvis and calyces had cyst-like shapes; the renal cortex was thin and the proximal part of the bilateral ureters were expanded; the bladder was enlarged, showing smooth wall (likely neurogenic bladder).

fied mutations of the AVP-NPII gene are shown in Table III and Fig. 4.
Function prediction of the mutated gene. The c.50 C>A and c.127 $\mathrm{C}>\mathrm{G}$ mutations may cause a moderate impairment in 


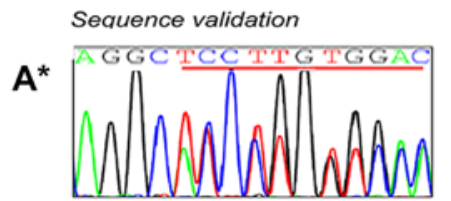

Sequence alignment

AGGAIGCCTGACACC

AGGATGCCTGACACC

AGGA.GCCTGACACC

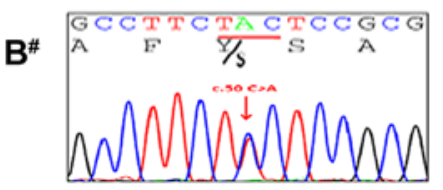

GCCTTCTㅡㄷTCCGCG

GCCTTCTㅡㄷTCCGCG

GCCTTCTACTCCGCG

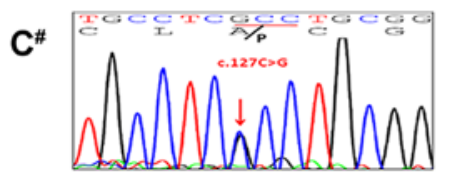

TGCCTCㅌCCTGCGG

TGCCTCㅌCTGCGG

TGCCTCGCCTGCGG

$\mathrm{D}^{\#}$

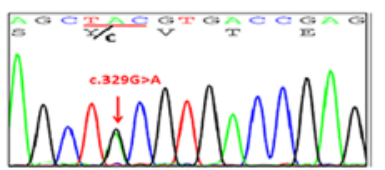

$E^{*}$

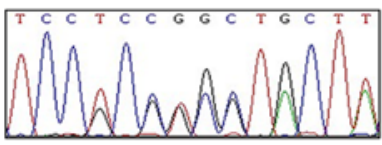

AGCTGCGTGACCGAG

AGCTGCGTGACCGAG

AGCTACGTGACCGAG
TTCTCCICCGCGTGCTACTTC TTCTCCTCCGCGTGCTACTTC

TTCTCC... GCGTGCTACTTC

Figure 3. Sequencing and localization of mutation on the arginine vasopressin-neurophysin II (AVP-NPII) gene of the familial neurohypophyseal diabetes insipidus (FNDI) probands. (A) Proband NYH; (B) proband QSH; (C) proband CC; (D) proband CSY; (E) proband GJY. In parts marked by an asterisk (*), red arrows indicate the start of deletion mutations; and in parts marked by a hash symbol (\#), red arrows indicate the missense mutation.

protein function, while the c.329C $>$ A mutation may induce a severe impairment in protein function.

\section{Discussion}

The present study revealed five novel AVP-NPII gene mutations, including c.2delT, c.50C $>\mathrm{A}, \mathrm{c} .127 \mathrm{C}>\mathrm{G}, \mathrm{c} .329 \mathrm{C}>\mathrm{A}$ and c.52-54delTCC. The functions of three missense mutations were predicted using PolyPhen-2 software and it was found that the c.50C $>\mathrm{A}$ and $\mathrm{c} .127 \mathrm{C}>\mathrm{G}$ mutations may cause a moderate impairment in protein function, while the c.329C $>$ A mutation may induce a severe impairment in protein function.

Of note, the age at disease onset in the patients was highly variable, and posterior pituitary MRI did not provide a consistent and definite diagnosis of FNDI. It is known that age at onset of FNDI varies greatly in both adults and juveniles. Indeed, a retrospective analysis of 408 cases of CDI conducted by $\mathrm{Gu}$ et al revealed that the majority of childhood/juvenile cases of CDI appeared between the ages of 8 and 12 years, while the majority of adults exhibited an age at onset ranging from 25 to 35 years (7). Consistent with these findings, Russell et al reported that the age at onset for typical autosomal dominant FNDI is highly variable (8). The present study demonstrated a high variation in the age at onset, which ranged from 3 to over 50 years of age, suggesting that a combination of yet undetermined genetic and environmental factors may contribute to symptom progression. While no apparent genotype-phenotype correlations have previously been reported, it has been suggested that specific $A V P-N P I I$ signal sequences may be associated with the delayed onset of symptoms, demonstrated by the low cytotoxicity associated with certain mutants in murine knockin models of FNDI (8). Thus, the five novel mutations described herein may provide a basis for future attempts to determine a link between the genetic variations in FNDI and the onset of symptoms.

In the present study, $50 \%$ of the FNDI cases were also diagnosed with mental retardation and associated delayed puberty. This relatively high rate of mental retardation may result from the stress placed on the hypothalamus-pituitary axis due to excessive water consumption, which causes a persistent chronic hyperosmotic state, leading to anorexia, insufficient energy supply and impeded developmental processes (9). Due to the risk of developmental disorders, early intervention with medications, such as desmopressin acetate is essential to achieve good clinical outcomes (9). This further highlights the need for early diagnosis and symptoms prediction, which requires careful cataloguing of FNDI genetic components.

Theoretically, plain MRI of the posterior pituitary reveals short T1 and high-intensity signals in normal individuals,

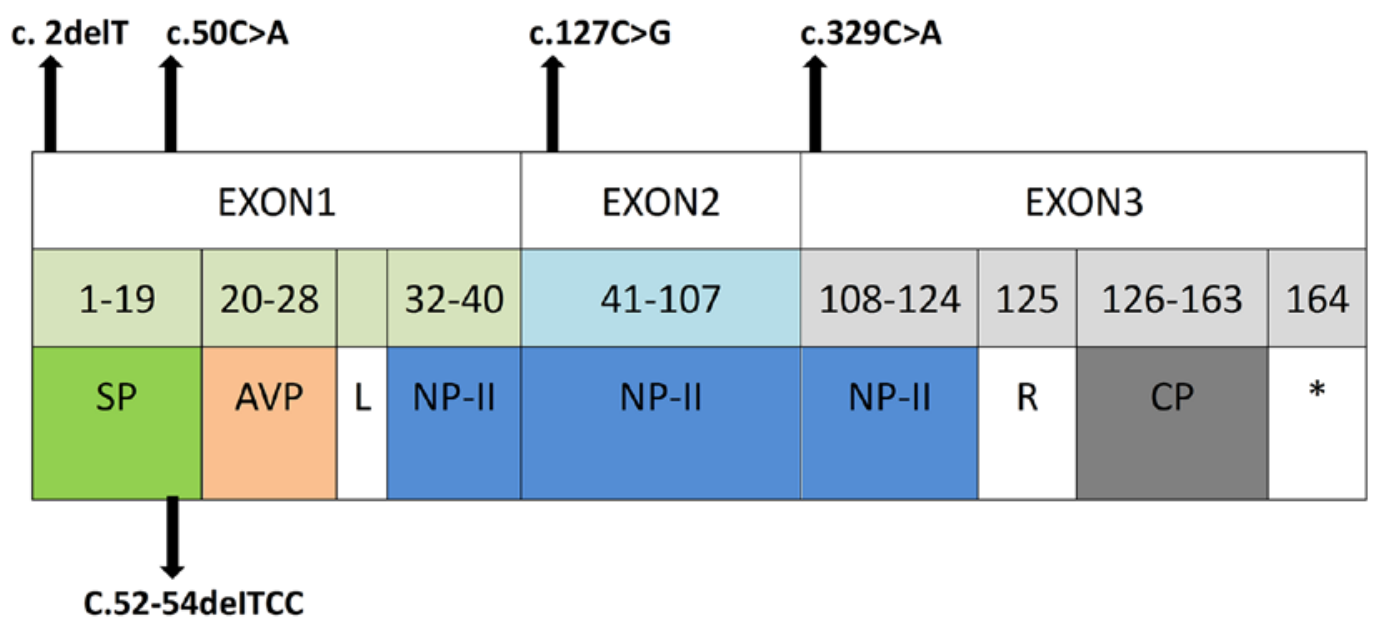

Figure 4. Localization of newly screened mutations on the arginine vasopressin-neurophysin II (AVP-NPII) gene. SP, signal peptide; AVP, arginine vasopressin; L, Gly-Leu-Arg; NP-II, neurophysin-II; R, arginine; CP, copeptide; *, stop codon. 
while such signals are absent in patients with FNDI; however, a study of 79 patients with CDI with a median follow-up of 1.5 years (0.2-7.5 years) demonstrated that posterior pituitary MRI hyper-intensity signals disappeared in $6 \%$ of the patients (9). Thus, CDI cannot be excluded based on MRI alone (10). In addition, pituitary stalk thickening, most commonly considered a secondary symptom of infiltrative lesions and autoimmune diseases, may obscure the diagnosis of CDI (10). Furthermore, a previous study suggested that thinlayer MRI scans of the sellar region at 3- to 6-month intervals would allow for correct diagnosis in $86 \%$ of patients in a 2 -year follow-up (7). Thus, MRI scanning cannot be considered a reliable substitute for biochemical and genetic analyses in children with suspected FNDI, which emphasizes the necessity for improved diagnostic strategies.

The sudden relief of CDI-associated symptoms without obvious reasons is indicative of the aggravation of CDI (7). Indeed, transient apparent relief of diabetes insipidus has been reported in untreated patients with panhypopituitarism; however, the limited ability of the kidneys to remove excess water in patients with hypocortisolism results in the masking of the clinical manifestations of diabetes insipidus. Hence, hydrocortisone replacement therapy likely plays a major role in the recurrence of diabetes insipidus. The correlation between panhypopituitarism and autosomal dominant FNDI may be casual; however, patients with autosomal dominant FNDI with alteration of diabetes insipidus symptoms require routine anterior pituitary function tests (9). A severe loss of AVP has been reported in some middle-aged male patients with normal anterior pituitary function, in whom the manifestations of diabetes insipidus (polydipsia and polyuria) vanish spontaneously, although the mechanisms involved are still unclear (11).

The reported $A V P-N P I I$ gene mutations include single- or double-base substitution, and depletion of several small-fragment bases (11-14). Of these alterations, AVP-NPII gene missense mutation is the most commonly detected (at least 62 types), while mutations in the SP region are rarely observed (approximately 6 types) $(11,13)$. While most FNDI cases are autosomal dominant, recessive forms have been reported on AVP peptides exhibiting the c.C301T (P26L) mutation (15). Furthermore, microsatellite analyses of screened $P 26 \mathrm{~L}$ mutations revealed that autosomal recessive FNDI exhibits identical homozygous genotypes for D20S906, D20S842 and D20S193 markers flanking the AVP-NPII gene on chromosome 20 (15). Despite the similarities in the types of mutations observed between previous studies and the present study, the patients exhibited largely variations in the age of symptom onset, suggesting that the underlying factors in symptom development require further investigation.

The two pedigrees observed in the present study exhibited a definite family history of FNDI, with the c.2delT mutation in the $A V P-N P I I$ gene being detected in the proband from one pedigree. This mutation may be responsible for abnormal methionine transcription (M1_T4del) and start codon shifts, as previously reported in the mutation of the signal peptide (SP) region encoded by the $A V P-N P I I$ gene (11). In 1996, an analysis of a Swiss pedigree of autosomal dominant FNDI revealed for the first time a novel single-base depletion g.227delG in the translation initiation codon of the AVP-NPII SP on one allele (16). Notably, the same changes were detected in the present study, likely due to abnormal transcription of the start codon (M1_T4del) and frameshift mutation within the open reading frame. Furthermore, in vitro homologous expression demonstrated that this mutation causes start codon shifting to the intra-frame structure, leading to depletion of the first 4 SP amino acids (17). Similarly, the encoded truncated SP can be transferred to the endoplasmic reticulum; however, mutations of the signal peptidase are rare. As a result, the undeleted SP may interfere with cys20-cys 25 disulfide bond formation of the AVP pre-prohormone, affecting nucleoprotein monomer folding and dimerization (18). A consistent mutation of the AVP-NPII gene (c.50C $>\mathrm{A})$ was detected in the proband from one of the pedigrees in this study; his mother exhibited serine 17 mutation to tyrosine (p.S17Y) on the signal peptide SP-3. Considering that tyrosine has a benzene ring, these findings suggest that the secondary structure of the encoded protein following gene mutation varies, which may, in part, account for the variability of clinical presentations.

The integrity of the $A V P-N P I I$ gene structure is critical for the correct folding and dimerization of proteins. It has been demonstrated that the 10th to 76th amino acid residues of NPII are highly conserved by ethnic groups, while the 10th to 27th amino acid residues are found to be critical for correct pro-AVP transport (19). Importantly, in the present study, both the c.127C $>$ G mutation (p.P43A) on NPII-12 and the c.329C $>A$ mutation (p.C110Y) on NPII-79 of the pre-pro-AVP were identified. Nonsense mutations have been previously described in the latter locus.

Functional studies on missense mutations-coding proteins are limited; however, it is speculated that the NPII sequence contains 14 cysteine residues, which is of great significance for disulfide bond formation and the maintenance of the secondary structure (18). As shown above, the 110th cysteine was mutated into tyrosine, thereby interfering with normal disulfide bond formation. Thus, these two mutations may cause structural and functional abnormality in mutant AVP due to the alteration of important amino acids, ultimately leading to clinical manifestations of CDI. However, the present study did not provide evidence for specific clinical manifestations due to specific mutations. Nevertheless, the c.52-54delTCC mutation (p.S18del) located on SP-2 may be involved in the destruction of SPs and abnormal intracellular transport of the AVP precursor hormone (19).

Two mechanisms have been suggested for NPII-induced polyuria, which has been demonstrated to involve mutant AVP proteins detained in the endoplasmic reticulum, and aggregation of mutant proteins may exhibit a cytotoxic effect, leading to further depletion of neuronal AVP cells and apoptosis in patients with FNDI (8). Alternatively, mutant NPII may cause polyuria, suggesting a dominant negative regulation of mutant NPII proteins $(20,21)$. It should be noted that although cell death is not the primary cause of progressive polyuria, it may lead to neuronal depletion (21). Hence, the mechanisms underlying apoptosis induced by the aggregation of mutant AVP precursors in the endoplasmic reticulum merit further investigation. Although the above-mentioned findings do not completely explain the FNDI pathogenesis, they provide additional and specific details pertaining to the number of mutations in the AVP-NPII gene. Thus, these findings provide additional insight into the molecular characterization of FNDI. 
Taken together, the findings of this study provide a molecular basis for AVP-NPII gene characterization, and may contribute to the growing body of work aimed at developing presymptomatic FNDI diagnostic methods.

The major limitations of this study were the limited sample size and the lack of epidemiological data. In addition, the MRI scan of saddle area was performed in six patients and it could not rule out that organic pituitary lesions caused diabetes insipidus in the remaining four patients. Furthermore, possible deficiencies of other pituitary hormones were not assessed, as they can also affect body water balance. The only difference between FNDI and INDI is that FNDI has a clear familial/hereditary component. Nevertheless, we cannot exclude the possibility that specific gene-gene or gene-environment interactions protect some individuals or cause the disease in some other patients. Therefore, some patients diagnosed with INDI may be in fact cases of FNDI, but additional studies are necessary to better characterize the disease and discover these interactions.

In conclusion, the characterization of five novel $A V P-N P I I$ mutations (c.2delT, c. $50 \mathrm{C}>\mathrm{A}$, c. $127 \mathrm{C}>\mathrm{G}, \mathrm{c} .369 \mathrm{G}>\mathrm{A}$ and c.52-54delTCC) in patients with FNDI is a critical step in determining the involvement of genetic components in CDI symptom onset and progression. In addition, these findings provide a basis for understanding the molecular characteristics of AVP and enhance the current understanding of the pathogenesis of FNDI. Furthermore, these findings provide new data for the development of presymptomatic diagnostic methods in the future. As undiagnosed FNDI represents a significant developmental risk, particularly in very young patients, the identification of the role of specific $A V P$-NPII mutations is a critical public health concern.

\section{Acknowledgements}

This study was supported by a grant from the National Natural Science Foundation of China (no. 81170724).

\section{References}

1. de Fost M, van Trotsenburg AS, van Santen HM, Endert E, van den Elzen C, Kamsteeg EJ, Swaab DF and Fliers E: Familial neurohypophyseal diabetes insipidus due to a novel mutation in the arginine vasopressin-neurophysin II gene. Eur J Endocrinol 165: 161-165, 2011.

2. Kronenberg $\mathrm{H}$ and Williams RH: Williams textbook of endocrinology. Saunders/Elsevier, Philadelphia, PA, 2008.

3. Wesche D, Deen PM and Knoers NV: Congenital nephrogenic diabetes insipidus: The current state of affairs. Pediatr Nephrol 27: 2183-2204, 2012.

4. Lee YW, Lee KW, Ryu JW, Mok JO, Ki CS, Park HK, Kim YJ, Kim SJ, Byun DW, Suh KI, et al: Mutation of Glu78 of the AVP-NPII gene impairs neurophysin as a carrier protein for arginine vasopressin in a family with neurohypophyseal diabetes insipidus. Ann Clin Lab Sci 38: 12-14, 2008.

5. Ye D, Dong F, Lu W, Zhang Z, Lu X, Li C and Liu Y: A missense mutation in the arginine-vasopressin neurophysin-II gene causes autosomal dominant neurohypophyseal diabetes insipidus in a Chinese family. Clin Endocrinol (Oxf) 78: 920-925, 2013.
6. Duzenli D, Saglar E, Deniz F, Azal O, Erdem B and Mergen H: Mutations in the AVPR2, AVP-NPII, and AQP2 genes in Turkish patients with diabetes insipidus. Endocrine 42: 664-669, 2012.

7. Gu F, Jin Z and Zhang D: The etiology and clinical characteristics of central diabetes insipidus, a retrospective study of 408 cases. Zhonghua Yi Xue Za Zhi 81: 1166-1171, 2001 (In Chinese).

8. Russell TA, Ito M, Ito M, Yu RN, Martinson FA, Weiss J and Jameson JL: A murine model of autosomal dominant neurohypophyseal diabetes insipidus reveals progressive loss of vasopressin-producing neurons. J Clin Invest 112: 1697-1706, 2003.

9. Brachet C, Birk J, Christophe C, Tenoutasse S, Velkeniers B, Heinrichs $C$ and Rutishauser J: Growth retardation in untreated autosomal dominant familial neurohypophyseal diabetes insipidus caused by one recurring and two novel mutations in the vasopressin-neurophysin II gene. Eur J Endocrinol 164: 179-187, 2011.

10. Fujisawa I: Magnetic resonance imaging of the hypothalamicneurohypophyseal system. J Neuroendocrinol 16: 297-302, 2004.

11. Babey M, Kopp P and Robertson GL: Familial forms of diabetes insipidus: Clinical and molecular characteristics. Nat Rev Endocrinol 7: 701-714, 2011.

12. Ito M, Mori Y, Oiso Y and Saito H: A single base substitution in the coding region for neurophysin II associated with familial central diabetes insipidus. J Clin Invest 87: 725-728, 1991.

13. Luo Y, Wang B, Qiu Y, Zhang C, Jin C, Zhao Y, Zhu Q and Ma X: Clinical and molecular analysis of a Chinese family with autosomal dominant neurohypophyseal diabetes insipidus associated with a novel missense mutation in the vasopressinneurophysin II gene. Endocrine 42: 208-213, 2012.

14. Christensen JH and Rittig S: Familial neurohypophyseal diabetes insipidus - an update. Semin Nephrol 26: 209-223, 2006.

15. Abu Libdeh A, Levy-Khademi F, Abdulhadi-Atwan M, Bosin E, Korner M, White PC and Zangen DH: Autosomal recessive familial neurohypophyseal diabetes insipidus: Onset in early infancy. Eur J Endocrinol 162: 221-226, 2010.

16. Rutishauser J, Böni-Schnetzler M, Böni J, Wichmann W, Huisman T, Vallotton MB and Froesch ER: A novel point mutation in the translation initiation codon of the pre-pro-vasopressin-neurophysin II gene: Cosegregation with morphological abnormalities and clinical symptoms in autosomal dominant neurohypophyseal diabetes insipidus. J Clin Endocrinol Metab 81: 192-198, 1996.

17. Beuret N, Rutishauser J, Bider MD and Spiess M: Mechanism of endoplasmic reticulum retention of mutant vasopressin precursor caused by a signal peptide truncation associated with diabetes insipidus. J Biol Chem 274: 18965-18972, 1999.

18. de Bree FM and Burbach JP: Structure-function relationships of the vasopressin prohormone domains. Cell Mol Neurobiol 18: 173-191, 1998.

19. Siggaard C, Rittig S, Corydon TJ, Andreasen PH, Jensen TG, Andresen BS, Robertson GL, Gregersen N, Bolund L and Pedersen EB: Clinical and molecular evidence of abnormal processing and trafficking of the vasopressin preprohormone in a large kindred with familial neurohypophyseal diabetes insipidus due to a signal peptide mutation. J Clin Endocrinol Metab 84: 2933-2941, 1999.

20. Si-Hoe SL, De Bree FM, Nijenhuis M, Davies JE, Howell LM, Tinley H, Waller SJ, Zeng Q, Zalm R, Sonnemans M, et al: Endoplasmic reticulum derangement in hypothalamic neurons of rats expressing a familial neurohypophyseal diabetes insipidus mutant vasopressin transgene. FASEB J 14: 1680-1684, 2000.

21. Arima $\mathrm{H}$ and Oiso $\mathrm{Y}$ : Mechanisms underlying progressive polyuria in familial neurohypophysial diabetes insipidus. J Neuroendocrinol 22: 754-757, 2010. 